\title{
An Aligned Alliance in Allegiance to the Drum Beat of Higher Education's Transformation Agenda: A Critical Discourse Lens
}

\author{
Anita Maürtin-Cairncross \\ Academic Leadership and Communications, University of the Western Cape, \\ P. Bag X17, Bellville 7535, South Africa \\ amaurtin-cairncross@uwc.ac.za
}

Doi:10.5901/mjss.2014.v5n6p233

\section{Abstract}

This paper includes an overview of transformation challenges faced by Higher Education globally, nationally and provides concluding remarks of the urgency that all staff who works in this sector understands and exemplify the transformation agenda. The study is contextualized within the framework of the critical discourse analysis (CDA) paradigm. This interpretive conceptual framework allows for the discussion of perceptions and interpretations of reports, debates and relevant document to substantiate arguments. Current trends in transformation in Higher Education, principles and goals of Higher Education Transformation in South Africa and several policy imperatives to drive the transformation agenda are discussed through a critical discourse lens.

Keywords: academics and administration support staff, higher education, transformation agenda

\section{Introduction}

The $21^{\text {st }}$ century has presented its own unique challenges on the Higher Education sector. These challenges includes changing student profiles (generation $Y$, older students entering universities, diversity of students with regard to academic fames of reference and life experiences); changing roles and responsibilities of staff (academics and administration support staff); funding and public accountability; the integration of technologies into teaching and learning; changes in the higher education landscape changes with regard to mergers of institutions (for economic reasons). All these factors have a direct impact on the transformation agenda of Higher Education, at national and global levels.

In South Africa, Transformation in Higher Education has been receiving attention at various fora. There have been commissioned reports, debates and commission of inquiry established to explore, understand and address the transformation agenda. The debates and interventions emanating from these fora are indeed thought provoking and elucidate the urgency for a thorough understanding of the shifting landscape of the Higher Education sector by all staff who works in these environments.

The purpose of this paper is to illustrate the urgency of the transformation agenda especially in the South African Higher Education sector in order for these institutions to be the beacons of leadership of transformation to assist in the sustainability to jealously guard our hard-fought for democracy. This paper also includes an overview of transformation challenges faced by Higher Education globally, nationally and provides concluding remarks of the urgency that all staff who works in this sector understands and exemplify the transformation agenda.

\section{Conceptualization and Contextualization of the Higher Education Transformation Agenda}

The success in the achievement of the Higher Education Transformation agenda is not located in a specific area but in the alliance of students, academic staff, administrative support staff, senior management and councils of universities. The success of the transformation is thus a shared responsibility and an aligned understanding of the importance of this responsibility. 


\subsection{Conceptualise Higher Education (HE) in relation to historically disparities}

\subsubsection{A global view of $H E$}

The positioning higher education institutions to ensure they contribute to the enhancement of economic performance are a key issue for many governments (Graig and Gunn, 2010). These authors provide a theoretical perspective associated with the notions of the knowledge economy which they emphasise the positive contribution to productivity and growth that comes from educating a large workforce with higher-level skills. However, this convention is being challenged through the phenomenon of offshoring, which threatens to unpick this relationship as highly skilled jobs become more geographically mobile.

\subsubsection{A South African overview of HE sector}

Transformation needs to be contextualized within the historical backdrop of apartheid education. Much has been said about the racial stratification of universities prior to 1994 which facilitated a dual system that combined advanced education for whites with under-developed and inadequate education for other racial groupings (Bunting, 1994; Cooper and Subotzky, 2001; Fernando, Hartley, Nowak and Swinehart, 1990; Wolpe, 1988). Black education was granted lower state funding than white education and subsecluently the 'non-white education' systems were inadequately resourced by the dominant political dispensation. The inadequacies and inequalities in this system of separatist education reflected and reproduced the socio-economic disadvantagement that was experienced by the disenfranchized racial groupings. Even in the disadvantaged sector of the education system there was a distinct hierarchy in the allocation of resources ;among the HBUs: universities that were established for coloureds and Indians were better resourced than those for blacks (Bunting, 1994; Cooper and Subotzky, 2001). A total of ten HBUs were established after the Extension of University Act in 1953. These institutions have been understood within three broad categories (Subotzky, 1997). The first category included the six black universities which were located in the rural areas (Universities of: Venda, Zululand, Transkei, the North, Fort Hare and the North-West); the second comprised of two HBUs located in the urban areas, one for coloureds (University of the Western Cape), the other for the Indians (University of Durban-Westville); and the third category of HBUs was established for specific purposes, one to train medical personnel for the treatment of black people (Medical University of South Africa) and the other, al distance -based university to cope with the increasing numbers of black people who required access to university education (University of Vista). Although significant strides have been made to attain an equitable system, remnants of these historical differences are still apparent in HBUs (Cooper and Subotzky, 2001; de la Rey, 1999; Singh, 2001; Subotzky, 2001).

In March 2002, the National Commission on Higher Education made proposals for the restructuring of the South African Higher Education sector (CHE report, 200/2001). The recommendations were tabled with the Minister of Education who presented these proposals to parliament for debate in order to implement them as law. These recommendations were legislated in October 2002. Some of the major areas of contention, which were heatedly debated, centered around the 'landscape of Higher Education' which has been recommended by the then Minister of Education. Many of these recommendations included the mergers of Historically Disadvantaged Institutions, (HDIs), while many Historically Advantaged Institutions (HAls) retained their established status. The implementation of these recommendations is currently underway at various levels in South African Higher Education. Thus in South African Higher Education and especially in HBUs where, although the playing fields are levelled since 1994, but where, in reality, funding and resources remain a challenge as HBUs strive to make up ground with HWUs to reach the levels of financial stability, create research cultures, broaden access with providing support to students and improve administrative and infrastructural processes. It therefore goes without saying that in these institutions, ordinary people are expected to do extra-ordinary things.

In this context, the one needs to understand the origins and current state of South African HBUs in relation to Historically White universities (HWUs). HWUs were resourced and funded significantly more than HBUs. Some programmes were also excluded from the offerings at HBUs. In the Western Cape, where there are three traditional universities, two were classified as HWUs (one a predominantly English (UCT) and the other a predominantly Afrikaans (US) ), and the third was an HBU (UWC ${ }^{1}$ ). Since 2006, a university of Technology, (the Cape Peninsula University of Technology) has been established which developed from the merger of the two technikons, namely Pentech and

\footnotetext{
1 The late Prof Jakes Gerwel termed UWC as the 'intellectual home of the left 'referring to this institution where black students would have a 'home' to develop critical thinking skills and where leaders for the democratic South Africa would emerge from.
} 
Capetech.

Since 2010, the Department of Education has been divided into two separate departments, each with their respective Ministers, namely Department of Basic Education and a Department of Higher Education and Training. The restructuring into two separate departments was developed by the government for the Department of Higher education and Training to have a direct and specific focus on Higher Education. The reasons for the specific focus included the implementation of the mergers, which were introduced for more efficient use of resources, infrastructural facilities and thus equalize the playing fields of Higher Education, as it were. By implication, these developments were directly and indirectly aimed at the ultimate goal of transformation.

\subsection{Challenges faced by Higher Education Institutions}

In 2008, the then Minister of Education, Ms Naledi Pandor, appointed a Ministerial Committee on Transformation and Social Cohesion and Elimination of Discrimination in Public Higher Education (Report on Ministrial Committee for Transformation, 2008). The Committee was headed by Prof Crain Soudien, and given the brief to "investigate discrimination in public higher education institutions, with a particular focus on racism, and to make appropriate recommendations to combat discrimination and promote social cohesion." The Committee had to report to the Minister on the following:

- An overview of the state of anti-discrimination in higher education;

- An indication of the most egregious forms of discrimination that are taking place within the system;

- The nature and extent of racism and racial discrimination in public higher education, and in particular university residence, and other forms of discrimination based on gender, ethnicity and disability;

- An insight into models of good, anti-discriminatory practices that were emerging within the system;

- An agenda for the areas of higher education most urgently in need of anti-discriminatory work, and steps that have to be taken by institutions to combat discrimination, including an assessment of good practice as well as short comings of existing interventions;

- An identification of the most critical areas for further investigation and research; and

- The Committee was to advise the Minister and the key constituencies in higher education on policies, strategies and interventions needed to combat discrimination and to promote institutional culture for staff and students, which are based on the values and principles enshrined in the Constitution.

The Committee's report (the 'Soudien Report') concluded that the state of transformation in higher education was painfully slow. In particular, racism and sexism were pervasive, while the pace of redress was equally painfully slow. It noted serious disjuncture between policy and real-life experiences of both students and staff, particularly in learning, teaching, curriculum, languages, residence-life and governance. Based on its conclusion, the Committee recommended as one of the key interventions, that "The Minister should consider establishing a permanent Oversight Committee to monitor the transformation of higher education."

According to the Report on the Ministerial Committee on Transformation (2008) the purpose of the proposed Oversight Committee would be to monitor progress on transformation in public universities and to advise the Minister on various aspects including development of policies to: reduce the incidence of racism, sexism and other forms of discrimination; promote social cohesion in institutional environments ; promote the role of universities for the development of a free, fair and non-discriminatory society beyond the world of academia. This committee understood Transformation in this broader sense to perforce be the aim of the entire system of governance and management at the national and institutional levels.

The mere fact that such a Ministerial Committee was established may allude to the phenomenon that the Higher Education sector is fraught with diverse, disparate and competing tensions and may be likened to a 'melting pot' of variables which have to be understood. These factors have a direct and critical impact on this terrain and cannot be in silo's or as separate factors. The 'ingredients' of this melting pot have to be understood, analysed and interpreted in relation to each other and as a conglomerate which make up the and contribute to the 'shifting sands' experience.

The melting pot comprises of an understanding of inter alia, the importance of : knowledge generation (the research agenda), the scholarship of teaching and learning, student support and holistic student development, generational characteristics of students, curriculum renewal and design with the infusion of technologies into teaching and learning environments), the first year experience versus high school, the Higher Education landscape at institutional, South African, African and global levels. And the list can continue.

Given the 'melting pot 'of Higher Education, it is imperative that all staff are cognizant that we and the students 
have, are the transformation agents. There are some schools of thought that purport that current students entering university are under-prepared for university. We have to realize that the students entering our gates and who are sitting in our classes are the crème-de-la-crème of their matric class. They are the ones who made it to Higher education, the few compared to the multitude who entered grade one in the same year they did, who did not even make it to high school. We, as the staff in Higher education one and all, need to understand the value of our students. They are as it were the 'gold bullions' and thus we need to realize that they need to be nurtured, supported and developed into the leaders of tomorrow.

A further ingredient of the melting pot of the South African Higher Education landscape is the impact of the remnants of SA's apartheid legacy. This political dispensation resulted in the social constructs of previously disadvantaged communities and Historically Black Universities (HBU)s. These realities inevitably have to be accommodated in the Higher Education sector. This has resulted in students who are first generation graduates, who are the pride and joy and often sponsored by their families, their villages and their communities.

\section{Methodological Considerations}

In this paper I have reviewed current literature to substantiate the urgency of the transformation agenda in Higher Education. Given that our fledgling democracy is fraught with challenges, universities have a pivotal role to play with regard to providing direction and leadership in South Africa context.

\subsection{Research paradigm critical discourse analysis (CDA)}

The study is contextualized within the framework of the critical discourse analysis (CDA) paradigm. This interpretive conceptual framework allows for the discussion of perceptions and interpretations of reports, debates and relevant document to substantiate arguments.

\subsection{Research design and procedures- desktop review and documents analysis (critical content analysis)}

A desk top review of several literature studies were conducted to explore the current trends, understandings and challenges of implementing the transformation agenda globally in order to provide a contextualized understanding of the importance of the transformation agenda in the South African Higher Education sector. Key word searches included concepts such as 'transformation'; 'Higher Education'; South African Higher Education';' staff in Higher Education'. I made used of the search engines of Google scholar, ESCOHOST as well as the University of Western Cape (UWC) library for current literature on the phenomena being investigated.

\section{Critical Discourse Lens of the HE Transformation Agenda}

\subsection{Current trends in transformation in Higher Education}

The current debate of the transformation agenda in Higher Education in South Africa and globally undoubtedly suggest an increase in the influence of the market and the global neoliberal ethos, with the latter becoming dominant in the discourse of the HE sector and determining its direction. The debate on this subject is diverse and includes the following issues: First, massification (acceleration and expansion of higher education and increased access to it) has become a popular means to address the problem of elitism. It has created a higher education system that is to accommodate new kinds of students and students from previously underrepresented groups, including women, ethnic minorities, and mature students.

Second, inter-institutional competition has intensified, and this has resulted in university-state relations being recast in contractual terms. The outcome of this is increasing government control over HET.

Third, globalization and marketization have tilted the balance in higher education from "internal," essentially academic concerns, to "external" issues such as institutional positioning and reconfiguration of missions to ensure financial survival.

Fourth, the competitive environment introduced by globalization and marketization has, necessarily, resulted in the creation of new relations with students and users, reduction in per capita student subsidies and the replacement of students' block grants by loans and graduate tax. In this competitive environment, funding councils are increasingly using their authority to introduce mechanisms of accountability and control over teaching and research, by linking funding to 
outcomes.

Fifth, government departments, funding councils, and other agencies have developed strategic policies to reinforce the notions of "market" culture and resource allocation, which change HET into a quasi-market.

Furthermore, competitive values are currently being espoused and competition between and within institutions encouraged. However, additional government resources for higher education have not accompanied the increasing competition brought about by globalization, marketization, and internationalization.

\subsection{Policy imperatives to drive the transformation agenda}

Policies that are driven by the global market economy and new managerialism have been subjected to intense debate, notably the negative impact of these policies on developing countries. In South Africa, for instance, the government's 1996 Growth, Employment and Redistribution (GEAR) strategy, which aims to create jobs by increasing foreign investment, is clearly driven by global competitiveness and complies with World Bank macroeconomic principles. This is a major contradiction of the political agenda embedded in the government's Reconstruction and Development Programme (RDP) of 1994. This program was intended to address equity, reconstruction and development, including poverty alleviation. Thus, critics of GEAR argue that the government has turned from promoting a quasi-socialist critique of class society to a celebration of the "free market," in that GEAR is a policy that is supervised by the market.

The shift away from RDP to GEAR tends to compromise, albeit indirectly, equity and redress principles that guided the policy discourse prior to the first democratic elections and during the first 3 years of the post-apartheid era. The notion of free market, in particular, has promoted a spirit of competitive individualism that assumes that success is based entirely on individuals' merit (even among some of the previously disadvantaged groups). Competitive individualism, therefore, seems to provide an explanation of why the previously disadvantaged communities in post-apartheid cannot fairly compete with their previously advantaged counterparts. This growing belief in competitive individualism has had the effect of negating the reality that racial and gender inequities (and their effects on the poor African black majority) will be difficult to eradicate because of historical and institutionalized injustices.

Discussions about the impacts of the discourse of globalization and new managerialism on HET in South Africa largely reflect developments in countries such as the United States, United Kingdom, Australia, and New Zealand as well as several Asian societies. According to Jan Currie, even though globalization is termed differently in different contexts ("McDonaldization," "Toyotism," and "post-Fordism" or "neo-Fordism") and "each takes a slightly different form, they all emphasise economic efficiency, and there is a tendency towards homogenising practices." However, Currie warns that it may be too simplistic to reduce globalization to transnational homogenization, because the specific historical, political, cultural, and economic characteristics of each country influence the ways in which globalization has developed and continues to unfold.

As in other countries, the neoliberal economic order (globalization and new managerialism) in South Africa is shaping HET policy in various ways in the post-apartheid era. Thus, more than ever before, the HET sector is expected to respond to the increasingly globalized knowledge-intensive world of the twenty-first century. This is expected to pose huge challenges and serious dilemmas for decision makers. There is a concern, for example, that South African policy documents do not take into consideration sufficiently the impact of the global economy on the national economy. Thus, analysts are sceptical of the insistence that higher learning institutions (HLIs) produce "useful" knowledge for the global economic market without analyzing the implications of this for internal development and the basic needs of the population as a whole. The neoliberal view assumes that HET must satisfy the needs of an export-driven economy by producing technicians skilled in business, science, and technology. The opposing view assumes that HET policy must equalize access of different groups of students, run development programs, and change the composition of the staff of higher education institutions.

Analyses of governance and management styles as well as funding structures that characterize HET transformation after apartheid reflect trends in other countries that adapt to global competition. In South Africa, however, these trends also need to be located within the context of racial inequity that derives from policies in vogue before the democratic election of 1994.

\subsection{Principles and Goals of Higher Education Transformation in South Africa}

The transformation of HET in post-apartheid South Africa is underpinned by the following vision, principles, and goals: (1) overcoming social, political, and structural inequalities; (2) establishing a system that contributes to reconstruction and development; (3) creating mechanisms for increasing the participation of a range of constituencies; (4) developing 
structures for increased collaboration between government, labor, and the business sector in providing funding for higher education; and (5) promoting active participation by South Africa in globalization, marketization, and high technology.

Transformation of HET in South Africa focuses primarily on reform of the structures of the system itself (size, shape, governance, and funding) with a view to developing alternative structures. An issue that arose from debates concerning the HET sector was whether the binary system of universities versus technikons and technical colleges that existed before 1994 should be continued or whether it should be replaced by a unitary structure. This tension was resolved by the adoption of a middle-ground position, that is, a "single coordinated" system retaining some elements of a binary system. The reform would address elitism, as funding would no longer favor universities at the expense of technikons and technical colleges.

According to a report (Mayekiso, Nel, and Sheppard, 2013) on the Transformation Oversight Committee (ToC), constituted by the minister of DoHET, of all the universities the "long walk to transformation" would be hardest for Stellenbosch University, in particular because they were found to be the least transformed institution of Higher Education. When race and gender were put together, the study found that the Central University of Technology in the Free State best mirrored the national demographics (Mokogba, 2013).

\subsection{An agenda for broadened access for all students}

In South Africa a national imperative from the National Minister of Higher Education, Dr Nzimande is that Higher Education is to broaden access, but this is not where it ends. The broadening of access is to be accompanied with the proviso of the provision of support for success. Transformation of the Higher Education sector according to the Soudien report and the Jansen newspaper article (Mail and Guardian, 2013) is reported to be slow and it is often due to the delay in or the lack of sufficient implementation of the broad policy framework of the White Paper of 1997. The higher education system continues to face the following major challenges: (1) declining enrolment, which results in competition among HLIs for students; (2) decreasing public funding for higher education; (3) increasing student debt; (4) low student completion rate and low research output; (5) lack of policies on academic and program development; (6) lack of effective governance and management in some institutions; (7) disruptions of academic programs because of the financial and academic exclusion of some students; and (8) skewed full-time enrollment across study fields and programs.

Although the challenges outlined above affect historically advantaged institutions (HAls) as well as historically disadvantaged institutions (HDIs), the situation in HDIs is reaching a crisis. For example, declining enrolments, which is purportedly linked to cuts in funding, student debt, and lack of effective governance and management, are endemic in HDIs. Thus, the proposed institutional mergers and incorporations that affect mainly HDIs are defended on the grounds that many of these institutions are nonviable (because of declining enrolments) and lack effective governance and management (DBSA report, 2011). The DBSA also reports that while the higher education sector expanded rapidly between 1993 and 1999, student enrolment declined after 1999. This suggests that the idea of massifying the higher education sector, which was promoted by the National Commission on Higher Education (NCHE) of 1996, has not materialized. Moreover, between 1999 and 2002 Afrikaans HAls gained in student enrolment and that English HAls maintained enrolment levels but that historically black universities experienced substantial declines in student enrolment. We, as staff members in Higher Education, need to understand the realize the importance of every aspect of the student experience from application to graduation. Every staff member needs to understand their contribution to students' graduation- from the cleaners (who keep venues clean and fresh), the technical services staff who maintain the buildings and facilities, the laboratory assistants and IT technicians who ensure that equipment is safe and in working order in learning environments, the campus protection staff who provide and ensure security, the student administration staff who provide information and assistance, faculty office staff who provide guidance and teaching staff who facilitate learning. Thus, the entire staffs complements needs to be able to have 'skin on the ball' with regard to primary purpose of universities, namely, the production of knowledge evident by the graduation of students.

As staff, we have to be cognizant of the sacrifices made for these students to be at our institutions. We have to realize how we often, without knowing it, we are role models and thus our responsibility to be responsive and professional is increased. An illustration used by a staff member of the gravity of our (staff and students) shared responsibility to succeed, goes as: a student, who came from a rural community, and was studying as a residential university student only came home during the vacation periods. At the end of each recess period, as the student was preparing to return to campus, her grandmother would call her and show her the black dress (protected by a plastic sheath), that was hanging behind the grandmother's bedroom door. The grandmother's words 'the black dress is there and waiting for your graduation ceremony, my child' would follow her back to campus. These words would fill her mind and her heart in all her campus endeavours (submission of assignments, social activities, preparing for exams, decisions with regard to adding 
or deleting subjects which may have jeopardized her time to graduation). That grandmother's "black dress behind her bedroom door' must be as important to us as staff members to ensure that our students are supported in order for them to graduate. Our physical infrastructure, administrative processes, teaching and learning environments and institutional cultures in Higher Education must provide and create positive experiences for students and staff. In South Africa, social inequalities were embedded and reflected in all spheres of social life, as a product of the systemic exclusion of blacks and women under colonialism and apartheid. The higher education system was no exception. Social, political and economic discrimination and inequalities of a class, race, gender, institutional and spatial nature profoundly shaped, and continue to shape, South African higher education. Given this, South Africa's new democratic government committed itself in 1994 to transforming higher education as well as the inherited apartheid social and economic structure and institutionalising a new social order.

Post-1994, there has been a wide array of transformation-oriented initiatives seeking to effect institutional change. These have included the definition of the purposes and goals of higher education; extensive policy research, policy formulation, adoption, and implementation in the areas of governance, funding, academic structure and programmes and quality assurance; the enactment The challenges of transformation in higher education and training institutions in South Africa of new laws and regulations; and major restructuring and reconfiguration of the higher education institutional landscape and of institutions. These initiatives have often tested the capacities and capabilities of the state and higher education institutions and have affected the pace, nature and outcomes of change (DBSA, 2011).

The South African Constitution of 1996 and the 1997 Act and White Paper directed the state and institutions to realise profound and wide-ranging imperatives and goals in and through higher education. It was assumed that their progressive substantive realisation would contribute immeasurably to the transformation and development of higher education and society (DBSA, 2011)

\subsection{Creating an institutional culture of servant leadership and developing an organizational citizenship}

Organizational citizenship behaviour (OCB), defined... as behaviour that (a) goes beyond the basic requirements of the job, (b) is to a large extent discretionary, and (c) is of benefit to the organization" (Lambert, 2006). Moreover, Lee and Allen (2002) argue that OCBs are employees' behaviour that, although not critical to the task or job, serves to facilitate organizational functioning. When staff understands and are valued in their roles, the institutional culture is positively experienced and organizational citizenship behaviours are enhanced. The higher the levels of organizational citizenship, the more the 'alliance partners' are prepared to go the extra mile to ensure the achievement of the vision. And in South African Higher Education, in specific and Higher Education, in general, this vision is a dire component for the transformation of societies.

Staff development for all staff is therefore imperative to ensure that all staff members are as efficient and effective as possible in the roles they occupy. Institutional cultures have to be conducive for staff to experience their sense of selfworth and the value of their roles. Staff development is an essential component for staff to remain abreast in the dynamic and changing Higher Education landscape. Staff development will ensure that staff are able to make sense of the different and diverse 'worlds' we experience and have to operate in, in Higher Education. For example, students from diverse socio-economic backgrounds, staff from other countries, various cultures, differently abled people, the reasons that the numbers of women students drop considerably as they move from graduate to higher degrees.

On the other hand, Home Affairs minister, Naledi Pandor says one of the best ways to honour struggle heroes of the past is to improve the pace of transformation in the country's institutions of higher learning (SABC NEWS 2013).

\subsection{Inculcating a communicative responsiveness amongst staff}

It is the dual responsibility of each staff member as well as the institution that all staff are and feel 'engaged' and connected to the 'bloodline' of Higher Education. Van Wyk (2013), refers to 'dialogical spaces' and in this context, it is these spaces must be used by staff in working in the Higher Education arena, to engage and create common understandings about changing landscape of the Higher Education arena so that all staff in Higher Education have some understanding of the contexts of their institution and general trends Higher Education. Thus communication must be regarded as an important value in the Higher Education sector. Communication is a powerful mechanism of acknowledgement and affirmation of staff. There must be a recognition and respect for different expertise and uniqueness of roles and the integration of the various components of the 'alliance' in order for the 'centre to hold'. By a simple illustration, an administrator to a senior professor has the role of taking calls and liaising with internal and external stakeholders. The role of the senior professor is to supervise PhD students. These roles and ranks are very different. 
However, without the administrator (to take calls), the senior professor supervision sessions may be interrupted by having to take calls or answer queries from stakeholders. Moral of the story, each role is important in its own right and should be recognized for its contribution.

\section{Concluding Comment}

The Higher Education sector is undergoing many changes at various levels at global, national and institutional level. The South African Minister of Higher Education and Training has indicated that the focus of Higher Education should provide broaden access to students with specific support strategies to improve success and ensure transformation. Transformation is thus regarded as a key and critical component of the changing landscape of this sector. Therefore, the clarion call of Higher Education's transformation agenda must be heeded to by all. It is imperative that to achieve true transformation, the notion must be owned in the hearts and minds of all who work in this arena. It must thus be embedded into our lived realities and be interwoven into the fibre of all our dealings in every aspect of our roles and responsibilities. Notwithstanding the challenge of remaining relevant to society in our quest for knowledge generation and the shifting of the ideology that the university as an ivory tower to the university as an oil well and watch tower of the new economy. At UWC, our mission guides this process as it states' a place of quality, a place to grow from hope to action through knowledge'.

\section{The Way Forward ....Practical Implications}

South African Higher education institutions therefore need to consciously introduce strategies and practices into their daily operations that will support the Transformation Agenda being alluded to by the National Development Plan. These strategies will assist to fast track the redress processes that are direly required to sustain South Africa's fledgling democracy. UWC's rector, Prof O'Connell, succinctly made the analogy of a buck drinking water, and the way it 'bristles' with anticipation as it is on high alert for any eventually as it quenches its thirst. And so we, that is all staff, working in the Higher Education need to 'bristle' with a keen sense of awareness of the changes, trends and shifts in the Higher Education sector from the micro level (our roles, our institutions) to the macro level (southern hemisphere and globally). We as staff working in the HE arena must realize we are all leaders in our own circle of influence. We need to embrace our leadership roles in order to remain relevant and aligned to the transformation agenda.

\section{Acknowledgements}

I would like to thank Prof Micheal van Wyk for his guidance in the development of this manuscript and for re-awakening the author in me. The views expressed are those of the author and not those of the institution.

\section{Reference}

Bunting, I. (1994). A legacy of inequality Higher Education in South Africa. Cape Town: UCT press.

Cooper, D. \& Subotzky, G. (2001). The skewed revolution. Trends in South African Higher Education: 1988 -1998. Cape Town: The Education Policy Unit, University of the Western Cape.

Council on Higher Education (2001): Council on Higher Education: The State of Higher Education in South Africa. CHE Annual Report 2000/20001. Pretoria: Council on Higher Education.

de la Rey, C. (1999). Career narratives of women professors in South Africa. Doctoral thesis. Cape Town: University of Cape Town.

Lambert, S.J. (2006) Both art and science: Employing organizational documentation in workplace-based research. In Pitt-Catsouphes, M., Kossek, E.E., \& Sweet, S. (Eds.). The work and family handbook: Multi-disciplinary perspectives, methods, and approaches. (pp.503-525). Mahwah, New Jersey: Lawrence Erlbaum Associates.

Lee, K., \& Allen, N. J. (2002). Organizational citizenship behavior and workplace deviance: The role of affect and cognitions. Journal of Applied Psychology, 87(1):131-142.

The Development Bank of Southern Africa.The challenges in Transformation in Higher Education and training institutions in South Africa. http://www.dbsa.org/Research/Higher\%20Education\%20and\%20Training/

Mayekiso, T., Nel, H and Sheppard, C. (2013). Measuring equality and unequally. Mail and Guardian. http://mg.co.za/article/2013-12-05measuring-equality-unequally (accessed December 10, 2013).

Graig, J \& Gunn, A (2010). Higher skills and the knowledge economy: the challenge of offshoring. Higher Education Management and Polic,y 22(3): 107 -123

Fernando, L., Hartely, N., Nowak, M. and Swinehart, T. (1990). Academic freedom 1990. A Human Rights report. London: Zed Books Ltd. 
Ntshoe, I (2004). The Politics and Economics of Postapartheid Higher Education Transformation. Comparative Education Review, 48(2):202-221

SABCNEWS. 2013. Pandor urges improved transformation in higher education (accessed December, 10, 2013) http://www.sabceducation.co.za/index.php?option=com_content\&view=article\&id=1003:pandor-urges-improved-transformationin-higher-education\&catid=39: media-releases\&ltemid $=\overline{84}$

Singh, S. (2001). 'Intruders in the sacred grove of Science'? A critical analysis of women academics' participation in research in the humanities and social sciences. Doctoral thesis. Kwa-zulu Natal: University of Durban-Westvilie.

South Africa. Ministerial Committee on Transformation and Social Cohesion and Elimination of Discrimination in Public Higher Education Institutions, and Crain Soudien. Report of the Ministerial Committee on Transformation and Social Cohesion and Elimination of Discrimination in Public Higher Education Institutions. Department of Education, 2008.

Subotzky, G. (1997). The enhancement of graduate programmes and research capacity at the historically black universities. Summary of final report- Education Policy Unit, University of the Western Cape, July 1997.

Subotzky, G. (2001). Addressing equity and excellence in relation to employment: What prospects for transformative change in South Africa? Equity \& Excellence in Education, 34 (3):23-29

van Wyk, M.M. 2013. Exploring Students' Perceptions of Blogs During Teaching Practice Placements. Mediterranean Journal of Social Sciences 4(13): 525-533.

Wolpe, H. (1988). Race, class and the apartheid state. London: James Curry. 
